DOI 10.37882/2223-2982.2021.01-2.17

\title{
ПОИСК ИСТОЧНИКОВ ИНФОРМАЦИИ, КАК УСЛОВИЕ УЧЕБНО-ИССЛЕДОВАТЕЛЬСКОЙ ДЕЯТЕЛЬНОСТИ УЧАЩИХСЯ МЛАДШИХ КЛАССОВ
}

\section{SEARCH FOR INFORMATION SOURCES AS A CONDITION OF EDUCATIONAL AND RESEARCH ACTIVITIES OF PRIMARY SCHOOL STUDENTS}

\section{Tikhonova}

Summary: The article suggests ways to form the skills of younger students to use information sources, work with the collected information, describes practical situations that contribute to the research activity of students.

Keywords: junior high school student, sources of information, work with information.

\author{
Тихонова Любовь Александровна \\ Соискатель, Дальневосточный Федеральный \\ Университет \\ lubavushka25@gmail.com
}

Аннотация: В статье предложены способы формирования у младших школьников умений пользоваться источниками информации, работать с собранной информацией, описаны практические ситуации, способствующие исследовательской активности учащихся.

Ключевые слова: младший школьник, источники информации, работа с информацией.

со способами получения информации.

Поиск источников информации включает в себя следующие этапы:

- вспомнить всё, что известно по данной теме;

- изучить теоретический материал (энциклопедии, словари, книги, статьи в журналах...);

- посмотреть видеоматериал (художественные и документальные фильмы, телепередачи);

- обратиться к ресурсам сети Интернет;

- cпросить у других людей, понаблюдать;

- провести эксперимент [5, с.16].

На наших занятиях мы предлагаем детям набор карточек с картинками, на которых изображены потенциальные источники и способы (методы) получения информации: словарь, учебник, энциклопедия, инструкция, схема, учитель, родитель, эксперимент, анкетирование, анализ и синтез и т.д.

Для знакомства с источниками информации мы предлагаем ученикам игру. Суть игры в том, что дети выбирают карточки слепым методом, а потом пробуют рассказать как можно больше о том источнике информации или способе её получения, который изображён у них на картинке, а слушатели должны угадать, про какой источник информации идёт речь. Случается так, что ученик доступно называет узнаваемые признаки источника информации и дети его называют, но случается и так, что источник информации мало знаком автору, например:

- Этот источник информации можно найти на пол-

Случалось так, что некоторых детей данная задача ставила в тупик, до того, как мы начинали знакомиться 
ке в библиотеке. В нём много слов.

Дети начинают предполагать [4, с.60]:

- Книга..,словарь...

Автор, конечно, ответы не принимает, так как её источник информации - орфографический словарь.

К сожалению, или к счастью, больше ученица ничего не могла сказать о том источнике информации, который был изображён на её карточке.

Возникает проблемная ситуация [3, с.12] и в этот момент подключается учитель:

- Друзья, вы близки к ответу. Кто-то назвал "словарь", но ответ не был принят. Почему, как вы думаете?

\section{- Может, толковый словарь?}

- Ещё ближе, но нет. Давайте вспомним! Недавно, на уроке русского языка мы изучали такой раздел науки, который отвечает за правильное написание слов. Кто помнит, как он называется?

\section{- Орфография.}

- Хорошо. Давайте подумаем, как тогда может называться словарь, который "дружит" с орфографией?

\section{- Орфографический!}

Всегда находятся ученики, которые с помощью подводящих вопросов [3, с.11], дают правильный ответ.

В такой ситуации процесс обучения закодирован на успех. Во-первых, у учеников в игре появляется азарт (А.М. Лобок), который стимулирует желание найти ответ, во-вторых, он активизирует механизм мышления, в-третьих, процесс сопровождается позитивными эмоциями. Поэтому, когда ученики находят ответ сами, он усваивается у них гораздо лучше, чем, если бы учитель просто назвал источник и рассказал о нём сам.

Чаще всего в такой игре трудности возникают при описании и угадывании способов получения информации. Такие понятия, как индукция, дедукция, аксиоматика и др. дети действительно слышат впервые. В таких ситуациях, безусловно, необходима помощь учителя, который с помощью диалога помогает учащимся самостоятельно найти ответ, а с помощью подходящих упражнений помогает закрепить новое знание.

После знакомства с источниками информации, ученикам предлагается выбрать те, которые необходимы для их собственного учебного исследования. Случается так, что ученики выбирают нужные источники информации. А бывает и так, что в процессе исследования этот список корректируется (какой-то источник может быть убран, какой-то добавлен...).

Например, ученик 2 класса, совместно с учителем, для проведения исследования по теме "Лучшая обувь для детей" определил следующие источники сбора информации: энциклопедия, общение с консультантами в магазинах детской обуви (опрос), эксперимент, интернет.

Хочется упомянуть, что к исследованию такой темы, ребёнка подвела мама. Ей хотелось, чтобы между ней и ребёнком исчезли разногласия при выборе обуви для ребёнка. Ей было важно, чтобы, в первую очередь, обувь была качественная и "полезная" для детских стоп.

В начале работы выбор источников информации происходил совместно с руководителем. Мы пользовались описанными выше этапами и выбрали энциклопедию, чтобы уточнить основные понятия, узнать об особенностях развития скелета в младшем возрасте, что необходимо соблюдать, чтобы развитие шло правильно. В интернете осуществлялся поиск информации самых популярных производителей детской обуви, лучших материалов для её производства. Общение с консультантами было организовано в виде опроса (Какая обувь в вашем магазине пользуется большим спросом? Что или кто влияет на выбор обуви? Какую обувь предпочитают выбирать дети? А какую родители детей? Какая обувь считается самой качественной в вашем магазине? В чём её особенность? ... ). Эксперимент предполагал наблюдения за состоянием сменной обуви одноклассников. На всех этапах исследования мама ученика принимала активное участие.

В исследовательской деятельности, в совместной работе учителя и учеников была создана памятка последовательности работы с собранной информацией:

1. Найти определение объекта исследования.

2. Собрать исторические сведения об объекте исследования, проследить его эволюцию во все времена.

3. Составить классификацию (по виду, по составу, по материалу, по жанру, по объёму...).

4. Изучить опыт других исследователей по исследуемому вопросу.

5. Получить информачию, используя выбранные методы исследовательской деятельности.

6. Сравнить полученную информацию с гипотезой исследования.

7. На основании полученных результатов сделать вывод.

Кроме того, мы используем метод конспектирования видео или аудио материала, работаем с таблицами, само- 
стоятельно определяя критерии её заполнения; учимся работать с учебником (находить информацию на развороте, в оглавлении); работаем со словарями. Еженедельно проводим урок литературы в библиотеке, по теме которого дети самостоятельно подбирают материал.

Например, на уроке окружающего мира при прохождении темы "Природные зоны России", мы предлагали детям видео-сообщения по разным природным зонам (одно занятие - одна зона) нашего государства. Дети слушали и смотрели видеозапись, а в своих тетрадях делали краткие записи, о климатических особенностях природной зоны в разное время года, об особенностях почвы, об особенностях растительного и животного мира, используя символы, знаки, зарисовки. Конспектировать получалось не у всех, кто-то успевал больше, кто-то меньше. Этот момент компенсировался работой в группах (по 4-5 человек): учащимся предлагалось представить доклад об особенностях природной зоны, по которой был составлен конспект, предложить иллюстрации к этому содержанию. Конспекты участников группы отлично друг друга дополняли, что приводило к большей информативности в иллюстрациях и докладах. Они сравнивали свои записи, определяли нужную информацию для доклада, чтобы не возникало повторений и, чтобы ниччего не упустить. Но больший эффект имел финал урока. Выбиралась (путём жребия) команда, которая начинала доклад первой, все остальные команды должны были внимательно слушать и делать анализ своих записей: отмечать то, что было сказано и то, что не прозвучало в ответе команды. Пометки все делали по-разному: знаком плюс, галочкой, подчёркиванием разным цветом, обводили в кружок и т.д. После команды подсчитывали количество отмеченной, несказанной информации. Поощрялись все команды, у которых были дополнения. Отмечалась та, у которой их было больше. Такая работа, как мы отметили, помогает детям лучше ос- воить новый материал, дальнейшее его чтение, ответы на вопросы происходит легче и осознанней.

Конспектировать мы учим детей на отдельных занятиях. Предлагаем им набор карточек с различными изображениями. Это могут быть люди разных возрастов и профессий, животные, растения. Или эти же герои, но уже в действии. Далее предлагаем изобразить знаком или символом то, что показано на картинке. Каждый представляет свой вариант, так как видит ребенок, возникает палитра способов конспектирования. При обмене мнениями, ученики интуитивно отмечают самые оригинальные символы, знаки, зарисовки, которые применяют в дальнейшем в своих конспектах. Например, на одном из занятий ребятам было предложено попробовать законспектировать несколько предложенных предметов, среди них была машина, Игорь Ш., особенно любивший рисовать, изобразил букву “M” с пририсованными к ней колёсами. Ребятам понравился его значок, они отметили, что буква и колёса помогут лучше запомнить слово. Некоторые ребята применили в своей дальнейшей практике способ конспектирования, предложенный Игорем.

Кроме всего, на всех этапах занятия, будь то новое знание или повторение, возможно использование информационно-коммуникативных технологий - компьютер, интерактивные доски [1, с.1]. Для подрастающего поколения инновационные технологии - норма.

Для учеников, у которых возникают большие трудности при работе с информацией, есть возможность обратиться за помощью, в первую очередь, к педагогу. Единого рецепта помощи таким ребятам нет, кроме внимательного отношения. Поэтому предлагаем решать возникающие трудности по факту, в соответствии с принципом [2, с.73] индивидуального подхода.

\section{ЛИТЕРАТУРА}

1. Кастерина 0.В., Поиск информации учениками начальных классов, 2013 [текст]. Режим доступа : https://nsportal.ru/nachalnaya-shkola/materialymo/2013/05/09/soobshchenie-po-teme-poisk-informatsii-uchenikami (дата посещения 12.02.2019).

2. Ковалева Т. М., Кобыща Е. И., Попова (Смолик) С. Ю., Теров А. А., Чередилина М. Ю. Профессия «тьютор». М.-Тверь: «СФК-офис». - 246 с.

3. Петрова Г.Н., Просветова Л.А. Диалог как условие обучения младших школьников умению находить проблему исследования и формулировать его тему [Текст] / Г.Н. Петрова, Л.А. Просветова // Сборник статей Международной научно-практическойконференции журнала «LINGVO-SCIENCE» (Варна, 10.01.2019 г.). - Варна: LINGVO-SCIENCE, 2019. - 27с. Режим доступа: http://lingvo-science.ru/wp-content/uploads/2019/02/Lingvo_journal_9.pdf (дата посещения 12.02.2019).

4. Петрова Г.Н., Просветова Л.А. Обучение младших школьников умениям формулировать цель, гипотезу и задачи в учебных исследованиях // Асаdетіс science - problems and achievements XVIII: Proceedings of the Conference/ North Charleston? 28-29.01.2019, Vol. 1 - Morrisville, NC, USA: Lulu Press, 2019 , p.131.

5. Савенков А.И. Стань исследователем: Рабочая тетрадь для самостоятельной исследовательской деятельности. - Самара: Издательский дом “Фёдоров", 2015. - 64с.: ил., 8 с. вкл. 